\title{
Relatos da estruturação de aulas remotas com a utilização de metodologias ativas
}

\author{
Artur Henrique Kronbauer, UNIFACS - UNEB, arturhk@gmail.com, \\ https://orcid.org/0000-0003-1151-9417 \\ Naiara da Encarnação Neves, UNEB, naiaraen@gmail.com, \\ https://orcid.org/0000-0002-3016-7069 \\ Pedro Henrique Pereira, UNIFACS, pedro.nis.ph@gmail.com, \\ https://orcid.org/0000-0002-3054-5787
}

\begin{abstract}
Resumo. O objetivo deste artigo é descrever a utilização de metodologias ativas em aulas remotas da disciplina de Interação Humano-Computador (IHC) durante a pandemia da Covid-19. As práticas pedagógicas, já utilizadas nas aulas presenciais, foram migradas para as aulas remotas com a intenção de potencializar a participação dos estudantes, criar formas de realizar avaliações formativas e continuadas, além de contribuir com experiências hedônicas positivas. A metodologia utilizada na pesquisa é de natureza aplicada, com uma abordagem qualitativa e de carácter exploratória. Para avaliar os resultados foi utilizada a técnica de autorrelato Self Assessment Manikin (SAM) que possibilita medir a experiência dos usuários (User eXperience - UX). Os resultados encontrados foram positivos e podem servir de exemplo para aplicações em outras áreas de conhecimento.
\end{abstract}

Palavras-Chave: Experiência do Usuário, Metodologias Ativas, Aulas Remotas.

\section{Reports of the structuring of remote classes using active methodologies}

\begin{abstract}
This paper aims to describe the use of active methodologies in remote classes of the Human-Computer Interaction (HCI) during the Covid-19 pandemic. Pedagogical practices, already used in face-to-face classes, were migrated to remote classes to enhance student participation, creating forms of formative and continued assessment, in addition to contributing to positive hedonic experiences. The methodology used in the research is of an applied nature, with a qualitative and exploratory approach. The Self Assessment Manikin (SAM) self-report technique was used to assess the results, which allows measuring the User eXperience (UX). The results found were positive and can serve as an example for application in other areas of knowledge.
\end{abstract}

Keywords: User eXperience, Active Methodologies, Remote Class.

\section{Introdução}

As instituições de ensino superior brasileiras estão utilizando o Ensino Remoto Emergencial (ERE) como forma de continuar suas atividades acadêmicas e contemplar o isolamento social decretado para minimizar o contágio da Covid-19. Foram várias as dificuldades enfrentadas neste período, sendo uma das mais importantes a compreensão 
de como replanejar uma disciplina ou reconstruir as aulas numa perspectiva ativa que combine atividades on-line e off-line, mediadas por tecnologias digitais e que possam ser individuais ou em equipe (De Araújo Silva et al., 2020).

Outro ponto de reflexão é a aplicação de avaliações de qualidade. Para alcançar este requisito, é necessário a utilização de diferentes métodos que avaliem tanto as características individuais do aluno como coletiva, tendo em vista que a função primordial da avaliação é identificar o nível de aprendizado. De posse dessa informação, o professor poderá reestruturar o seu trabalho com o intuito de fazer valer o real significado da avaliação: contribuir para o aprendizado e formação do aluno (De Sousa et al., 2018).

Segundo Rothen et al. (2020), a utilização do ensino remoto deverá se intensificar nos próximos anos em função de dois aspectos: o primeiro, relacionado a mudanças que já estavam ocorrendo na educação com o uso das tecnologias da informação; e segundo, por gerar, em determinadas situações, boas experiências na dinâmica do ensino-aprendizado, remodelando práticas pedagógicas vivenciadas na educação presencial. Sendo assim, é importante que as experiências e os novos arranjos pedagógicos colocados em prática emergencialmente sejam socializados, para que suas viabilidades, potencialidades e desafios sejam discutidos.

Neste sentido, o objetivo desta pesquisa é relatar e avaliar as práticas pedagógicas utilizadas para a condução das aulas de IHC, utilizando a modalidade de ensino remoto, para quatro turmas, dos cursos de Ciência da Computação e Sistemas de Informação, de uma universidade do nordeste do Brasil. As metodologias ativas utilizadas no decorrer do semestre foram: Gamificação, Sala Invertida, Atividade Extraclasse, Aprendizagem Baseada em Problemas, Projetos e Equipes.

Para verificar os sentimentos hedônicos provocados pela utilização das metodologias ativas, o estudo abrange uma investigação da User eXperience (UX), como forma de verificar e socializar as boas práticas pedagógicas utilizadas nas aulas remotas.

Como contribuições, espera-se que possa servir como base para a construção de práticas pedagógicas para outras disciplinas, em diferentes áreas, tendo como base as metodologias ativas, tornando assim o aluno protagonista do seu próprio aprendizado.

\section{Trabalhos Relacionados}

Para posicionar o leitor em relação aos trabalhos que estão sendo desenvolvidos para o ensino de IHC, durante o período da pandemia da Covid 19, que utilizam metodologias ativas em aulas remotas, no Brasil, foi realizada uma pesquisa bibliográfica exploratória, tomando como base o Google Acadêmico. O resultado foi a seleção de 5 artigos com propostas semelhantes as descritas neste estudo.

O estudo de De Oliveira (2020) relata as experiências da condução da disciplina de IHC em meio à pandemia em uma instituição privada de ensino no Brasil. As metodologias aplicadas foram a gamificação (Kahoot), Talk com convidados e Trabalho Prático em equipe. A avaliação qualitativa ocorreu ao longo do semestre, com a utilização de formulários online para perguntar a opinião dos estudantes sobre as aulas, estratégias adotadas e o que poderia ser melhorado. Os resultados apresentados demonstram que as ações foram avaliadas positivamente pelos estudantes, demonstrando que algumas das estratégias também podem contribuir para o aprendizado de IHC independente do ambiente: online, presencial ou híbrido.

Diniz et al. (2020) aplicou a metodologia de aprendizado baseado em projetos por meio da elaboração de protótipos interativos de alta fidelidade, baseados nas heurísticas de usabilidade de Nielsen. O projeto ocorreu em uma disciplina de IHC, nas modalidades de ensino presencial e remoto. A avaliação qualitativa ocorreu em forma de 
relatos dos estudantes, com a descrição de opiniões positivas relacionando a metodologia com aplicações práticas de mercado e o desenvolvimento de habilidade como, criatividade, liderança e trabalho em equipe.

O artigo de Marques et al. (2020) descreve a condução do curso de Usabilidade e UX no ERE. As atividades desenvolvidas mesclaram atividades Síncronas (S) e Assíncronas (A), contemplado Aulas Expositivas (S), Videoaulas (A), Leitura de Textos (A), Exercícios Práticos (A), Discussões dos Exercícios (A), Execução de Trabalho (A) e Apresentação de Trabalho (S). A avaliação foi conduzida por meio de um formulário de feedback, aplicado logo após o fim das atividades. As questões fechadas endereçaram a percepção dos alunos com relação aos elementos metodológicos do ERE. As questões abertas foram utilizadas para indicar problemas enfrentados e a intenção dos participantes em realizar outras atividades na mesma modalidade. Os resultados indicaram que a execução do trabalho prático foi um dos elementos da metodologia que mais contribuiu para o aprendizado. $\mathrm{O}$ principal problema reportado foi o recrutamento de pessoas para participar dos testes de usabilidade e das avaliações de UX.

Martinelli e Zaina (2021) apresentam uma abordagem baseada na Sala de Aula Invertida para ser aplicada no ensino de IHC para alunos de graduação e pós-graduação. A proposta é formatada em atividades síncronas e assíncronas, utilizando-se do uso das metodologias de Aprendizagem Baseada em Projetos e Aprendizagem Baseada em Problemas. A avaliação da experiência dos alunos ocorreu no meio e no final do curso, utilizando-se de questionários e entrevistas. Os resultados revelaram que os alunos ficaram satisfeitos, motivados e com o sentimento que absorveram o conteúdo ministrado, tanto nos momentos síncronos como assíncronos. A análise qualitativa do estudo revelou nove aspectos positivos e cinco negativos em relação ao desenho metodológico aplicado.

No relato de Viana et al. (2021) é utilizada a metodologia de Aprendizagem em Equipe para executar uma proposta pedagógica que possui 5 etapas: (i) selecionar 3 aplicativos para apoiar a prática de exercícios físicos durante o período pandêmico; (ii) escolher um dos aplicativos para analisar a sua interface e realizar um Projeto de Interface; (iii) fazer a avaliação de usabilidade do aplicativo; (iv) realizar uma avaliação de UX; e (v) realizar o redesign do aplicativo. O resultado da aplicação da sequência pedagógica na disciplina de IHC possibilitou um grande engajamento dos alunos na realização das atividades propostas, que tinham como objetivo atender às demandas de forma colaborativa. A conclusão dos autores é que a interação entre os alunos de uma mesma equipe permitiu o compartilhamento da aprendizagem individual dos conteúdos.

Os estudos apresentados enfatizam a relevância do tema de pesquisa e sugerem que a comunidade, pesquisadores e professores da área de IHC estão preocupados com a adoção de metodologias ativas que contribuam com a ERE. A socialização de suas experiências durante o período da pandemia do Covid-19 poderá trazer inúmeros benefícios para a adoção de práticas pedagógicas aplicadas e avaliadas durante este período histórico da humanidade. Os resultados observados poderão servir de base para a aplicação destas metodologias nas diferentes formas de ensino: presencial, remoto e híbrido.

Os trabalhos relatados buscam objetivos semelhantes ao apresentado neste artigo, entretanto uma diferença substancial está na diversidade de metodologias ativas utilizadas para a composição do desenho metodológico que será apresentado na Seção 4.

\section{Materiais e Métodos}

Esta pesquisa é de natureza aplicada com uma abordagem qualitativa e de característica exploratória, buscando descrever como os discentes participam das práticas 
pedagógicas propostas, como são suas experiências e os seus sentimentos, levando em consideração o lado humano da questão (Gil, 2002).

Em relação aos procedimentos adotados para a condução do estudo, podem ser destacados três:

- Pesquisa Participante, onde o próprio idealizador das práticas pedagógicas é o responsável por sua aplicação e avaliação, de forma contínua no decorrer do semestre.

- Revisão da Literatura, utilizada para apoiar esta pesquisa com evidências e aspectos científicos relatados por outros pesquisadores.

- Avaliação de UX, que é o processo adotado para avaliar os sentimentos hedônicas despertadas nos discentes.

A aplicação das metodologias ativas foi mediada por tecnologia, utilizando os recursos disponíveis no Ambiente Virtual de Aprendizagem (AVA), redes sociais (WhatsApp), pesquisa exploratória na internet, softwares para a criação de modelos conceituais, protótipos e aplicativos para smartphones.

A avaliação da UX com as práticas pedagógicas aplicadas no decorrer da disciplina tomou como base a técnica de autorrelato Self Assessment Manikin (SAM) que é baseada em um modelo psicológico que abrange as dimensões do prazer, excitação e dominância (Bradley; Lang, 1994). Apesar de existir dezenas de técnicas de autorrelato, a técnica SAM se destaca por permitir a investigação das três dimensões, o que se apresenta propício para as finalidades deste estudo.

A Figura 1 ilustra a técnica SAM que foi aplicada nas avaliações com o auxílio do Google Forms. O prazer varia da expressão de infeliz até muito feliz, em uma escala Likert de nove pontos. A excitação é representada por figuras que mostram muito desinteresse (concebido com um ponto no centro da figura) até muito entusiasmado (constituída com grande explosão). A dominância retrata o nível de controle sobre o contexto, representada pelo tamanho das figuras, sendo o máximo de controle a figura de maior tamanho.

Figura 1- Formato da técnica SAM.

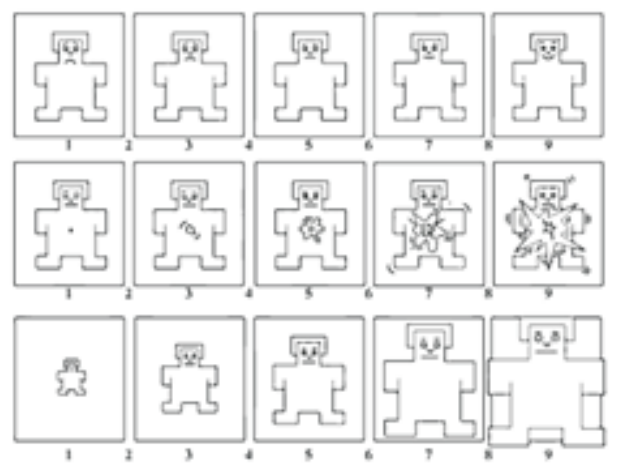

Fonte: Bradley e Lang (1994).

Para analisar os resultados encontrados no estudo, foram utilizadas algumas medidas estatísticas. A Média Aritmética, Mediana e Moda são utilizadas para identificar a concentração de escolhas na escala da técnica SAM. O Desvio Padrão é uma medida que expressa o grau de dispersão de um conjunto de dados. Quanto mais próximo de zero for o desvio padrão, mais homogêneo são os dados e se aproximam da média, quanto mais distante de zero for o Desvio Padrão, maior é a dispersão dos dados.

A pesquisa foi submetida ao Comitê de Ética em Pesquisa, devido a participação de seres humanos aprovada com o Parecer Consubstanciado de número 1.973.433. 


\section{Relato das aulas e aplicação das metodologias ativas}

Nesta seção, serão descritas as práticas pedagógicas diárias da disciplina e o formato da avaliação que foi conduzida com a aplicação de várias metodologias ativas.

Segundo as definições de Bacich e Moran (2018) podemos caracterizar cada uma das metodologias utilizadas nas aulas de IHC da seguinte forma:

- Sala Invertida - Trata-se de uma abordagem pela qual o aluno assume a responsabilidade pelo conhecimento, pelo estudo teórico e a aula presencial (neste momento realizada virtualmente através de vídeo conferência) serve como aplicação prática dos conceitos estudados previamente. O que é tradicionalmente feito em sala de aula é executado em casa e vice-versa.

- Aprendizagem Baseada em Problemas - Esta proposta defende a ideia de que a aprendizagem significativa deve ser baseada em apresentar problemas práticos para que os estudantes possam encontrar as soluções.

- Aprendizagem por Gamificação - Este conceito aplica a mecânica de competição para engajar e motivar os estudantes a participar das aulas.

- Atividade Extraclasse - Este mecanismo funciona como um complemento ao conteúdo ministrado nas aulas remotas e permite que os estudantes pratiquem e assimilem os temas abordados.

- Aprendizagem Baseada em Projetos - Esta abordagem é utilizada para aprimorar as habilidades dos participantes desenvolvendo artefatos e promovendo a interdisciplinaridade.

- Aprendizagem Baseada em Equipes - Corresponde a uma estratégia de ensino colaborativa aplicada em grupos. A ideia é que cada aluno tente entender individualmente os conceitos apresentados nas aulas remotas e reforce o aprendizado pela realização de atividades colaborativas com os demais colegas.

As metodologias ativas de ensino-aprendizagem foram adotadas para que os alunos desenvolvessem habilidades sobre os assuntos abordados, levando-os a melhorar e aperfeiçoar o processo de tomada de decisão, atitude, criatividade e senso crítico, além da participação em atividades colaborativas de conhecimento, transformando-os em protagonistas da sua própria educação (De Melo Figueiredo et al., 2020).

A seguir serão relatados os passos executados nas aulas remotas de IHC, levando em consideração as sequências de práticas pedagógicas executadas em cada aula.

- As aulas normalmente começam com uma introdução do conteúdo apresentado pelo professor, com a utilização de slides e vídeos. Na sequência, são escolhidos alguns alunos para a continuidade da explanação do conteúdo e a promoção de debates sobre o assunto, tomando como base os direcionamentos da Sala Invertida.

- Posteriormente, com as diretrizes da Aprendizagem Baseada em Problemas, são apresentados cenários que precisam ser remodelados com os conceitos de IHC vistos na aula. Os problemas propostos se caracterizam, por exemplo, em ajustes de interface, adequação de interações e soluções de acessibilidade.

- Após o assunto abordado em aula ser devidamente explorado, a próxima fase é a Gamificação que serve como avaliação formativa continuada. Esta metodologia é empregada em todas as aulas, possibilitando que os alunos respondam um questionário vinculado ao assunto explorado no dia, utilizando uma aplicação específica para gamificação denominada de Kahoot. Os alunos com maior pontuação no jogo são bonificados com pontos extras na disciplina.

- O próximo passo é apresentar as Atividades Extraclasse que os alunos devem realizar. As atividades são propostas no AVA, utilizando o fórum de discussões, com 
definição de exercícios que precisam ser resolvidos com o auxílio de vídeos e links para outros repositórios para que os alunos explorem novas fontes de informações.

- Por fim, são contextualizados os assuntos que serão tratados na próxima aula com a indicação do material que deverá ser estudado e preparado para uma possível apresentação, viabilizando a aplicação da Sala Invertida na aula subsequente.

As avaliações da disciplina foram moldadas seguindo as indicações de Pimentel e Carvalho (2020) que defendem avaliações formativas contínuas, voltadas para o aprimoramento dos saberes, apoiada na própria consciência do aluno em relação ao processo de aprendizagem, de tal maneira que os alunos percebam o que já aprenderam, quais são seus déficits e quais ações formativas devem realizar para supri-los.

Neste sentido, as realizações das avaliações foram pautadas nas metodologias de Aprendizagem Baseada em Projetos e Equipes. A proposta foi realizar uma avaliação continuada, ao longo do semestre, que viabilizasse a construção de um aplicativo para smartphone, para uma determinada área, escolhida por conveniência pelas equipes.

Na primeira avaliação os alunos entregaram um levantamento de requisitos que descrevia o cenário de atuação do aplicativo, com mapas mentais para correlacionar suas funcionalidades e protótipos de baixa fidelidade para ilustrar as interfaces. Para a segunda avaliação, as equipes entregaram um protótipo de média fidelidade para uma avaliação parcial e, posteriormente, um protótipo de alta fidelidade do aplicativo.

\section{Resultados e Discussões}

As práticas pedagógicas sugeridas neste estudo foram aplicadas em 4 turmas, contemplando uma carga horária de 66 horas em cada turma. Responderam ao questionário de UX 38 alunos, sendo 15 do matutino e 23 do noturno.

A primeira avaliação é referente a Satisfação, Motivação e Dominância dos alunos em relação a Sala de Aula Invertida. Ao analisar o gráfico da Figura 2, é possível verificar que existe uma grande dispersão nas avaliações das três dimensões da técnica SAM, comprovada estatisticamente com todos os Desvios Padrão em torno de 2,5. Esta informação, caracteriza diversidade de opiniões em relação a metodologia e demonstra a existência de alguns estudantes insatisfeitos, desmotivados ou inseguros.

Figura 2 - Análise da utilização da Sala Invertida.

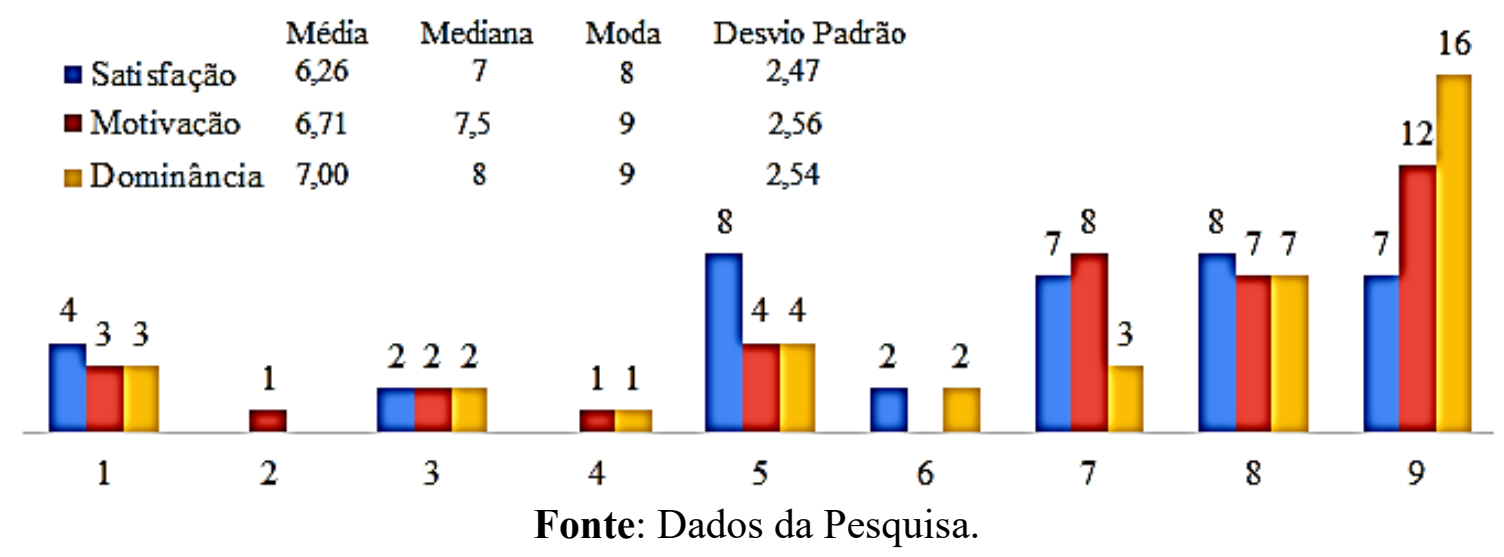

Este resultado pode estar vinculado a demanda da própria metodologia que exige que os estudantes conheçam profundamente suas atribuições, saibam trabalhar de forma colaborativa e sejam disciplinados. Além disso, aspectos emocionais decorrentes da 
exposição em público durante as apresentações, pode ser outro fator desencadeador de sentimentos hedônicos negativos (Valério; Moreira, 2018).

Apesar das constatações anteriores, observa-se no gráfico da Figura 2 maior concentração de respostas favoráveis a metodologia, considerando as três dimensões da técnica SAM, comprovadas pelas Médias acima de 6, Medianas entre 7 e 8 e Moda entre 8 e 9. Portanto, pode-se concluir que a Sala Invertida proporcionou uma UX positiva para a maioria dos participantes deste estudo.

A segunda análise refere-se à utilização da Aprendizagem Baseada em Problemas, levando em consideração as três dimensões da técnica SAM. Como ficou caracterizado na Figura 3 e nas medidas estatísticas, a opinião dos alunos concentra-se nas pontuações mais altas em relação a utilização da metodologia, caracterizando que os estudantes que participaram do estudo se sentem satisfeitos, motivados e dominam esta prática de ensino-aprendizagem.

Figura 3 - Avaliação da utilização da Aprendizagem Baseada em Problemas

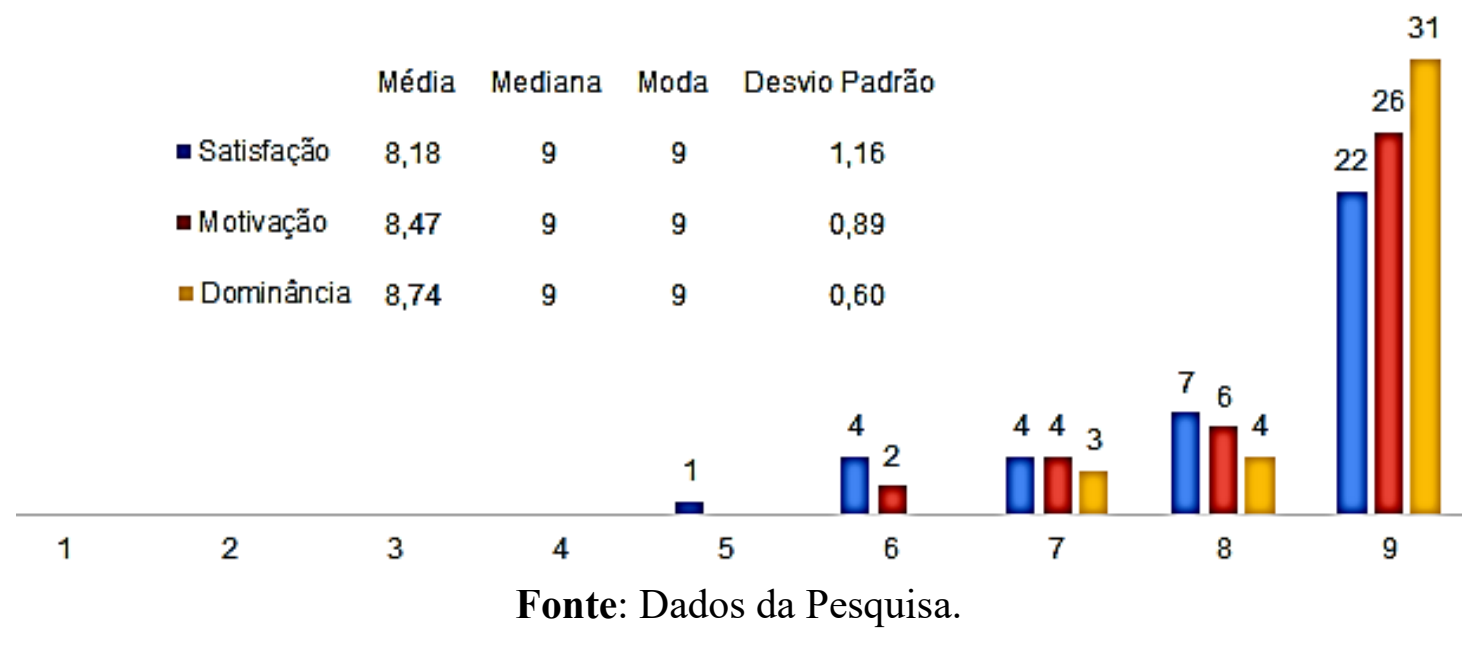

Os resultados das avaliações da Sala de Aula Invertida e Aprendizado Baseado Problemas reforçam as constatações de Fiorini et al (2020) e Martinelli e Zaina (2021), indicando que estas metodologias proporcionam aulas interessantes e participativas, além de destacarem que o professor pode dar feedback sobre os trabalhos fazendo com que as dúvidas, erros e acertos possam ser socializados com os demais alunos.

A próxima avaliação está relacionada com o uso da Gamificação como uma ferramenta lúdica para motivar e engajar os alunos a participarem das aulas remotas. Como pode ser observado no gráfico da Figura 4, existe uma dispersão de opiniões gradual, que inicia em uma pontuação neutra, em torno de 5 na escala da técnica SAM, e direciona-se para a pontuação máxima (9), onde está a maior concentração de opiniões. Esta leitura gráfica, pode ser validada pelos valores das variáveis estatísticas, com Médias acima de 7, Mediana 8, Moda 9 e desvio padrão entre 1,35 e 1,55. Estes dados comprovam que a Gamificação, utilizada nas aulas remotas de IHC, trouxe boas experiências hedônicas para os estudantes.

Este resultado corrobora com os evidenciados por Feichas et al. (2021), que realizaram uma revisão sistemática da literatura abrangendo a utilização da gamificação na área de Ciência da Computação. A constatação dos autores foi que a maioria das publicações apresentou resultados positivos com a gamificação, principalmente no engajamento e motivação dos estudantes. 


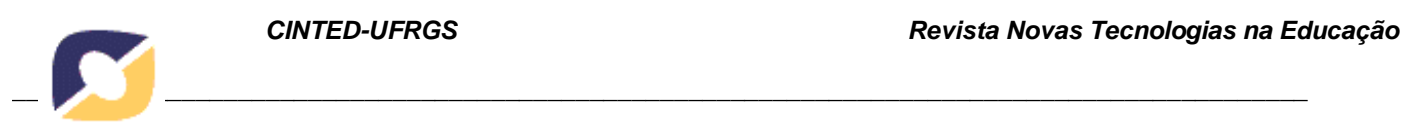

Figura 4 - Análise da experiência com a Gamificação

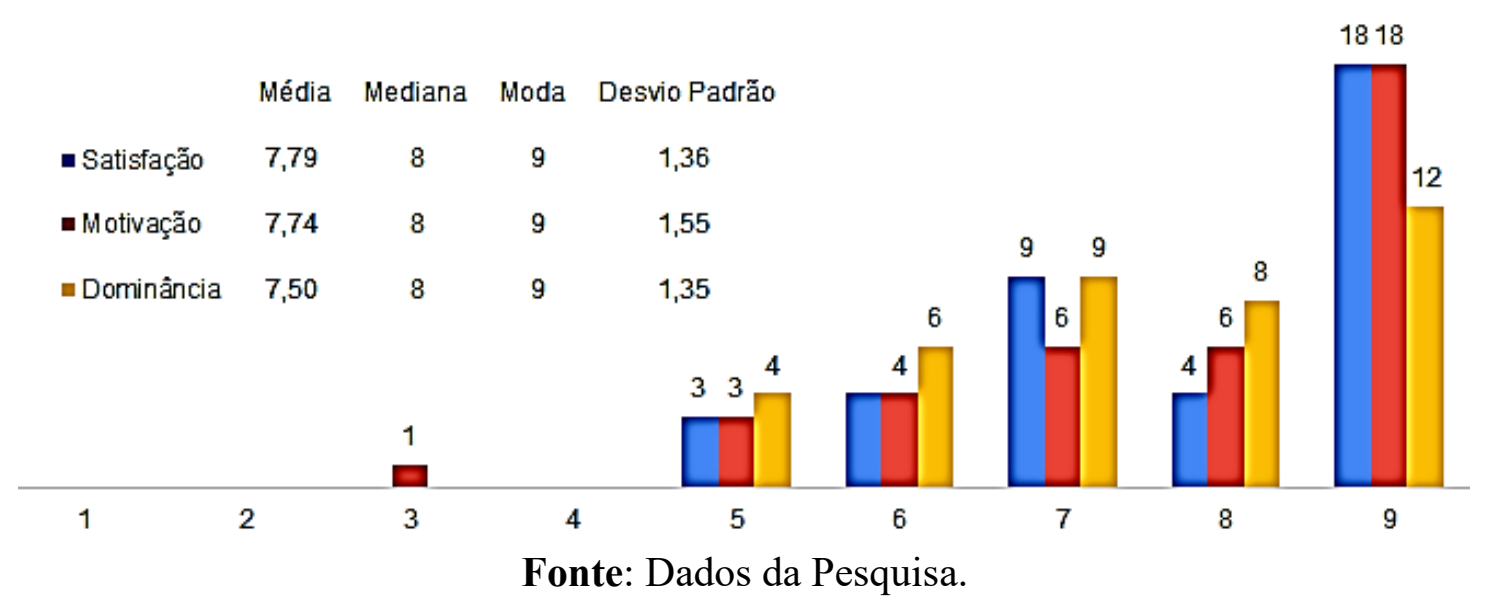

A análise da execução das Atividades Extra Classe, defendida por alguns autores como extensão da sala de aula, trouxe a maior dispersão de opiniões deste estudo. Esta informação pode ser confirmada pela análise gráfica da Figura 5, sendo possível constatar que as três dimensões receberam pontuação em todos os valores da escala da técnica SAM. Estatisticamente, esta informação pode ser comprovada pelos Desvios Padrão entre 2,2 e 2,9 .

\section{Figura 5 - Avaliação das atividades Extra Classe.}

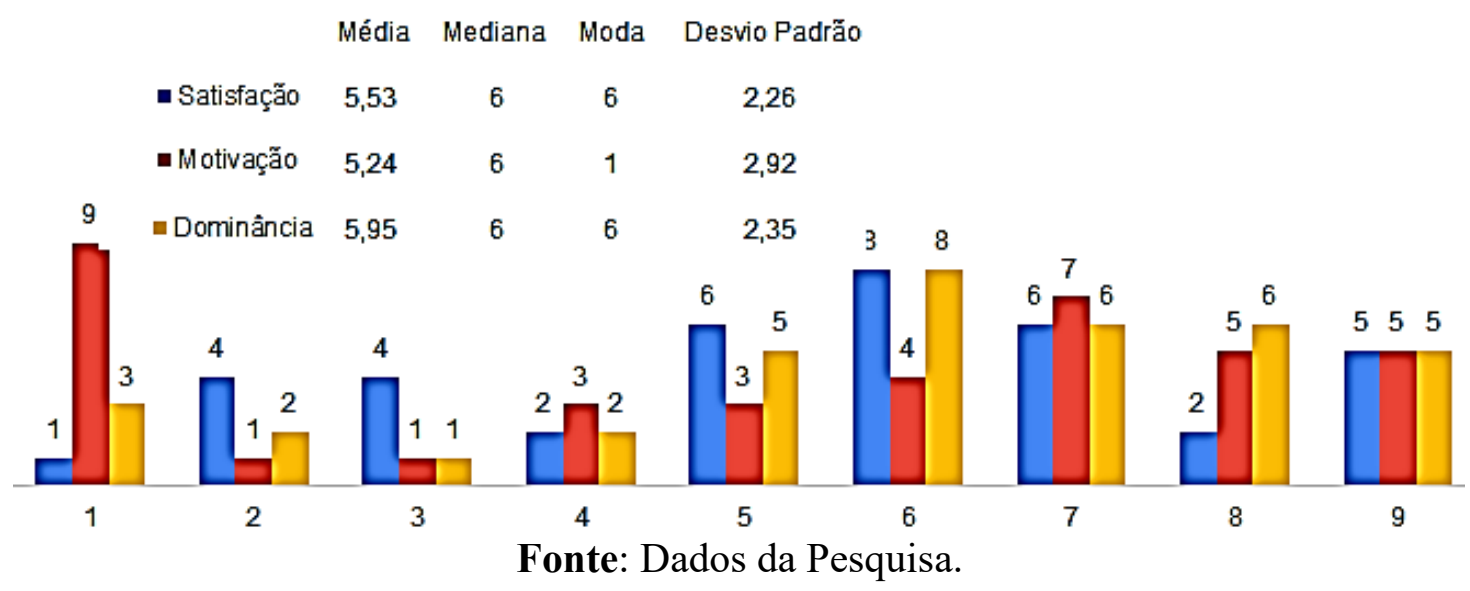

Outra observação importante é que as Médias, Medianas e Modas estão entre 5 e 6, para as três dimensões, o que caracteriza imparcialidade sobre a metodologia. Porém, o principal ponto a ser destacado é a Moda igual a 1, referente a Motivação, o que caracteriza grande desmotivação com a realização de Atividades Extra Classe.

Os resultados apresentados corroboram com o estudo desenvolvidos por Deslauriers et al. (2011) que ressaltam a falta de motivação para os estudantes resolverem atividades individuais e em suas casas. Isso nos leva a repensar a utilização desta metodologia e propor alternativas que possam incentivar a sua execução, tais como, a realização de atividades em equipes mediadas por tecnologia e de forma gamificada.

O último aspecto desta análise está relacionado com a avaliação formativa, continuada, que se apoia na aplicação de duas metodologias ativas principais, a Aprendizagem Baseado em Projeto e Atividades Baseada em Equipe.

Conforme pode ser observado no gráfico da Figura 6 e na análise das medidas estatísticas, as tendências das três dimensões são parecidas, com concentração no lado V. $19 \mathrm{~N}^{\circ}$ 2, Dezembro, 2021 DOI: https://doi.org/10.22456/1679-1916.121183 RENOTE 
positivo, o que demonstra nível alto de satisfação, motivação e dominância em relação as metodologias ativas aplicadas e a forma de avaliação realizada.

Este resultado demonstra uma boa UX dos estudantes com a aplicação das metodologias ativas que geraram produtos concretos, tais como, modelos mentais, protótipos de baixa, média e alta fidelidade, utilizados como forma de avaliar os conceitos absorvidos no decorrer das aulas. Esta evidência foi relatada em todos as pesquisas apresentadas na Seção de Trabalhos Relacionados.

Figura 6 - Análise da utilização de metodologias ativas nas avaliações.

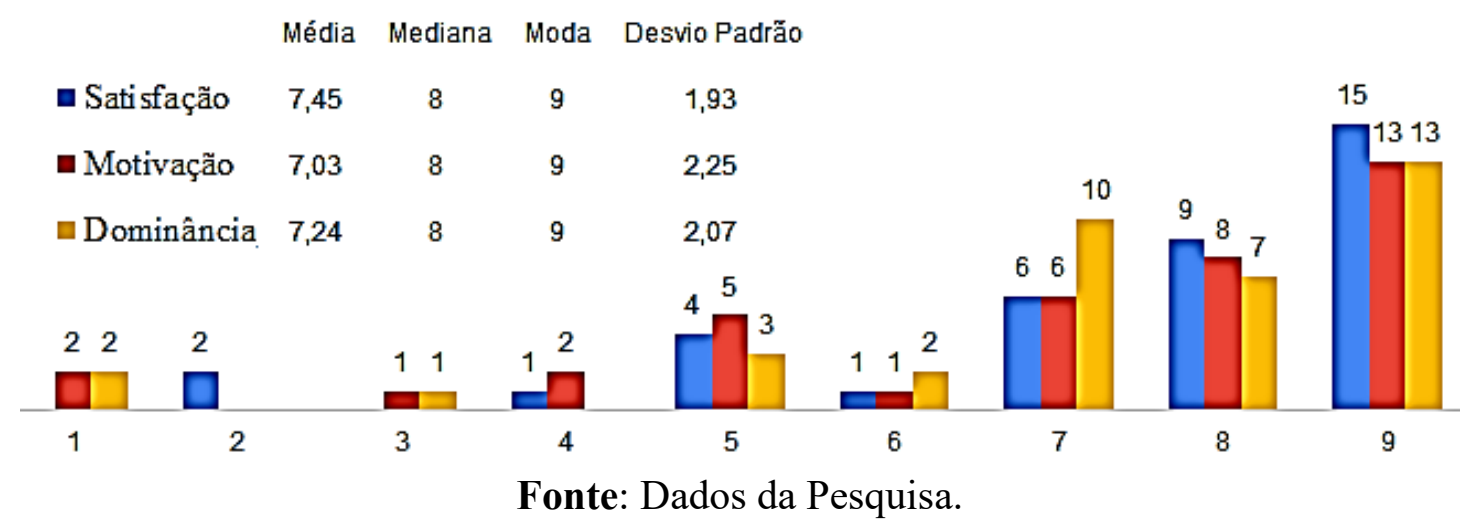

\section{Conclusões e Trabalhos Futuros}

Neste artigo, foi relatada uma sequência de práticas pedagógicas que envolvem diferentes metodologias ativas para a condução de aulas remotas e avaliações formativas e continuadas, tendo como objetivo potencializar o engajamento e participação dos discentes.

Outro aspecto a destacar, é a descrição de uma técnica de autorrelato, oriunda da UX, de fácil aplicabilidade, que proporciona aos docentes uma forma para mensurar se a condução de suas práticas pedagógicas está suprindo as expectativas do seu público-alvo, permitindo a detecção de possíveis mudanças no decorrer das aulas.

Os resultados da avaliação das práticas pedagógicas aplicadas nas aulas remotas de IHC, possibilitam concluir que os estudantes, participantes do estudo, apresentaram satisfação, motivação e dominância para a maioria das metodologias ativas utilizadas. Entretanto, não significa que a simples adoção de metodologias ativas em sala de aula prescinde de um bom sincronismo de conteúdo e do apropriado desenho metodológico da disciplina. O entendimento da dinâmica em sala de aula e consequente adesão dos alunos estão profundamente relacionados ao sucesso da condução da disciplina. Além disso, os resultados do estudo não podem ser generalizados, porque o público-alvo e o contexto foram escolhidos por conveniência. Esta particularidade, entretanto, não inviabiliza as contribuições deste trabalho que se propôs a descrever um desenho metodológico e uma forma de avaliar a sua aplicação, possibilitando que outros docentes possam replicar o estudo em suas turmas.

Como trabalhos futuros, pretende-se continuar as investigações em relação a adoção de metodologias ativas em aulas remotas, tendo em vista não somente verificar a visão dos discentes, mas incluir avaliações referentes aos sentimentos hedônicos despertados nos docentes. 


\section{Referências Bibliográficas}

BACICH, L.; MORAN, J. Metodologias ativas para uma educação inovadora: uma abordagem teórico-prática. Penso Editora. 2018.

BRADLEY, M. M.; LANG, P. J. Measuring emotion: the self-assessment manikin and the semantic differential. Journal of behavior therapy and experimental psychiatry, 25(1):49-59, 1994.

DE ARAÚJO SILVA, A. C.; DE QUADROS, C. I.; MARTINS, J. A aprendizagem durante a pandemia: muito mais que pedras no caminho da educação superior. Comunicação $\&$ Educação, 25(2):156-168, 2020.

DE MELO FIGUEIREDO, C. A. D.; DE OLIVEIRA, A. J. F.; FELIX, N. M. R. Metodologias ativas na formação de professores da modalidade de ensino a distância. Revista Paidéi@ - Revista Científica de Educação a Distância, 12(21): 168-180, 2020.

DE OLIVEIRA, E. R. IHC no Ensino Remoto Emergencial: Relato de Experiência. In Anais Estendidos do XIX Simpósio Brasileiro de Fatores Humanos em Sistemas Computacionais. SBC, 31-36, 2020.

DE SOUSA, L. D.; DE ALMEIDA, F. A., BARD, L. A.; CANCELA, L. B. Os desafios enfrentados pelos professores no processo de avaliação no ensino superior. Revista de Gestão e Avaliação Educacional, 7(16):59-66, 2018.

DESLAURIERS, L.; SCHELEW, E.; WIEMAN, C. Improved learning in a large enrollment physics class. Science, 332(6031):862-864, 2011.

DINIZ, L. M. F.; PEREIRA, M. V.; DE PAULA, L. J. D.; DE MELO SILVA, E. C. Aprendizado Baseado em Projetos em IHC (presencial e remoto): prototipação segundo as heurísticas de Nielsen. In: Anais Estendidos do XIX Simpósio Brasileiro de Fatores Humanos em Sistemas Computacionais. SBC, p. 13-18, 2020.

FEICHAS, F. A.; SEABRA, R. D.; DE SOUZA, A. D. Gamificação no ensino superior em ciência da computação: Uma revisão sistemática da literatura. RENOTE, v. 19, n. 1, p. 443 $452,2021$.

FIORINI, D.; DE ALMEIDA, I. C.; DAL FORNO, L. F.; GELLER, M. Sala de aula invertida apoiada pela gestão do conhecimento. RENOTE, v. 18, n. 2, p. 601-610, 2020.

Gil, A. C. Como elaborar projetos de pesquisa. Atlas: São Paulo, volume 4, 2002.

MARQUES, L.; MATSUBARA, P.; DE SOUZA FILHO, J. C.; GOMES, G.; GADELHA, B.; CONTE, T. Challenges and Learning from Remote Teaching of Usability and UX: An Experience Report. In: 19th Brazilian Symposium on Software Quality. p. 1-9, 2020.

MARTINELLI, S. R.; ZAINA, L. AM. Learning HCI from a Virtual Flipped Classroom: improving the students' experience in times of COVID-19. In: Proceedings of the XX Brazilian Symposium on Human Factors in Computing Systems. p. 1-11, 2021.

PIMENTEL, M.; Carvalho, F. d. S. P. Princípios da educação online: para sua aula não ficar massiva nem maçante. SBC Horizontes, 23, 2020.

VIANA, J.; NETO, B.; PORTELA, C.; SANTOS, I.; LOBATO, C.; SILVA, J. V.; VANZELER, J. Aprendizagem Baseada em Equipe Aplicada no Ensino Remoto na Disciplina de Interação Humano-Computador. In: Anais Estendidos do XX Simpósio Brasileiro de Fatores Humanos em Sistemas Computacionais. SBC, 2021. 